\title{
Teaching students what we do A collection management course
}

$I^{\mathrm{n}}$ n recent years, the landscape of collection management has been radically transformed by the explosion of digital content, the importance of collaborative initiatives for content acquisition and shared print management, new licensing and acquisition models, the dramatic shift in facilitating access versus ownership, and a crowded field of providers and platforms. The academic library itself has been utterly changed in the past two decades. What does this mean for the ways in which we teach the next generation of librarians about the activities, goals, and issues involved in collection management?

I have taught a collection management course three times, from 2010 to 2012, at the School of Information Studies at the University of Ottawa-Canada. The Master of Information Studies program was established in 2007, and the school is very proud to have received full accreditation from ALA in 2014.

\section{A few challenges}

Expectations of collections work are rapidly changing. As Peggy Johnson has noted, "User expectations about the services, collections, and access that libraries should provide are profoundly affecting collection development and management." ${ }^{\prime}$ LIS students need to be aware of business practices around e-resources licensing, vendor relations, and consortial dynamics and goals. Moreover, they have to become attuned to the bewildering variety of acquisition models for ebooks and preservation strategies for both ebooks and print books (and other materi- als), and to understand why these issues are so visceral for libraries. It is also essential for students to understand the impact of networked resources, scholarly publishing and the ever-evolving ecosystem of players in the supply chain, and budget constraints that are becoming tighter each year. With all of this knowledge, however, they need to learn how to stay close to the pulse of their patrons' needs and expectations. Therefore liaison work and partnership are central to success.

The challenge for anyone teaching collection management to LIS students is to articulate the paradigm shift from local collections to a networked and collaborative model, ${ }^{2}$ and to teach skills and methodologies that address the issues in a forward-looking and holistic manner. Understanding the impact of information abundance in a digital world and the reduced barriers to access is essential for students. We need to use pedagogical strategies to convey the new landscape, and articulate what it borrows or repurposes from the old. Therefore striking the right balance is essential for success, to illustrate how transformational and traditional thinking inform each other.

\section{Teaching LIS students}

The marrying of theory and practice is a difficult balancing act for any professional

Tony Horava is associate university librarian (collections) at the University of Ottawa in Ontario, Canada, email: thorava@uottawa.ca

๑ 2015 Tony Horava 
education. It is important to focus on learning goals and foundational knowledge with a view of how these issues play out in the real world of librarianship.

Being a practitioner with many years of experience in collection management gives me an intimate view of the challenges and opportunities. For example, informing discussions of vendor relations with real-life stories of negotiations (the good, the bad, and the ugly) was of real benefit for the students. They could see the links between interests and outcomes, and the impact on the range of resources that we license.

Students sometimes have very dated impressions of what it means to be involved in collections work; some have assumptions of spending significant time on title-by-title selection. They are unaware of the challenges of access versus ownership models in a digital era, the complexities of navigating scholarly communication issues, the impact of open access policies, and the necessities and challenges of acquiring and managing a wide range of new forms of knowledge, such as datasets, GIS resources, video streaming services, and visualization tools.

Some students imagine librarians and vendors in a two-tone world of good guys and bad guys. They were surprised at the difficult choices that need be made, such as reorienting the collection strategy in response to budget cuts or staff cuts, and what sustainability means in the 21st-century library. The smorgasbord of licensing models is a surprise for many students, as is the complexity of negotiating license agreements with vendors and the importance of being a skilled negotiator.

While students are learning the knowledge and principles behind collection management, it is important to convey a sense of these issues that they will have to confront once they are working in collections-related roles in their professional career. The exploration of library values was a frequent theme in class discussions, as students grappled with ethical challenges such as censorship, public policy issues, consortial dynamics, and vendor relations. The sheer interrelatedness of many issues and trends was a revelation for students.

It was also eye-opening for students to understand the critical importance of articulating the value of what we do, i.e., demonstrating that the significant financial investments made by our institutions in the collection, year after year, are essential for meeting the goals of scholarship and teaching. This opened doors to conversations about the role of collection assessment in our work, and different techniques and strategies to consider. It also led to an appreciation of the political dimensions of collection management, in an era of rapid change in educational technology, teaching methods, program learning outcomes, and research agendas. This broader landscape is important for students to grasp.

\section{Assignments}

I developed assignments that would enable students to learn as much as possible about the complexities and challenges of collection management. There was a selection assignment for which students were asked to assume that they were the Political Science selector in our institution, and that it was close to year-end with $\$ 1,500$ left to spend in the departmental budget. There was a case study assignment for students to focus on real-world scenarios and develop effective strategies in response, and there was a Great Debate assignment in which students were required to give a class presentation on a polemical proposition- "Be it resolved that the print book is dying and should no longer be a major focus for collection management." These active learning assignments were wellreceived and allowed students to engage with the issues by applying their analytical skills, judgement, and creativity.

I gave term paper topics that would enable students to explore current issues, e.g., E-books: The tipping point to success; The implications of Google Books for collection management; Print on demand technology: Implications for collection management; The (continues on page 130) 


\section{Research and Scholarly Environment}

Goal: Librarians accelerate the transition to a more open system of scholarship.

- Approved ACRL Plan for Excellence objective change to include the removal of objective four, "create and promote new mechanisms that reward and value open scholarship."

\section{Enabling Programs and Services}

- Endorsed new strategic initiatives for CHOICE and the capital expenditures to support them.

- Reviewed the FY14 year-end financial report, the first quarter FY15 report, and the preliminary draft of the FY16 budget.
- Established a Digital Scholarship Centers Interest Group to provide a forum for discussion and the exchange of ideas related to digital scholarship centers.

- Decided to pilot holding a virtual spring meeting of the full ACRL Board on April 17 rather than a face-to-face meeting of the Executive Committee.

- Heard plans for the next membership survey and focus groups, as well as ideas about how to increase member engagement.

("Teaching students what we do," cont. from page 127)

patron-driven acquisition model for books; Re-defining the nature of a 'library collection' in the 21st century; New forms of scholarly communication: Their impact on collection management ; and, Determining the value of consortial acquisitions for the library collection. I used Peggy Johnson's Fundamentals of Collection Development and Management as the course textbook; it provided a superb overview of broad themes, incorporating historical and current knowledge, as well as case problems in a variety of different library settings.

\section{Conclusion}

Teaching what we do is a challenge in any era, but it is particularly challenging in today's world. The collection management practices that have guided us for decades are being rapidly reinvented. From a professor's perspective, instilling critical thinking, creativity, analytical skills, and curiosity are paramount. Teaching collection management to the next generation of librarians and information professionals has been a privilege and very rewarding. It has allowed me to share my knowledge and experience, while I found myself being challenged by students' ideas and perspectives. All the more power to them, as they will be the ones to redefine collection management in the coming years.

\section{Notes}

1. Peggy Johnson, Fundamentals of Collection Development and Management, 2nd edition (Washington: ALA, 2012), 25.

2. "21st Century Collections: Calibration of Investment and Collaborative Action: Issue Brief," Association of Research Libraries, Last modified March 10, 2012, arl.org/storage /documents/publications/issue-brief-21st -century-collections-2012.pdf, accessed August 14,2014 . n 